Provided for non-commercial research and education use. Not for reproduction, distribution or commercial use.

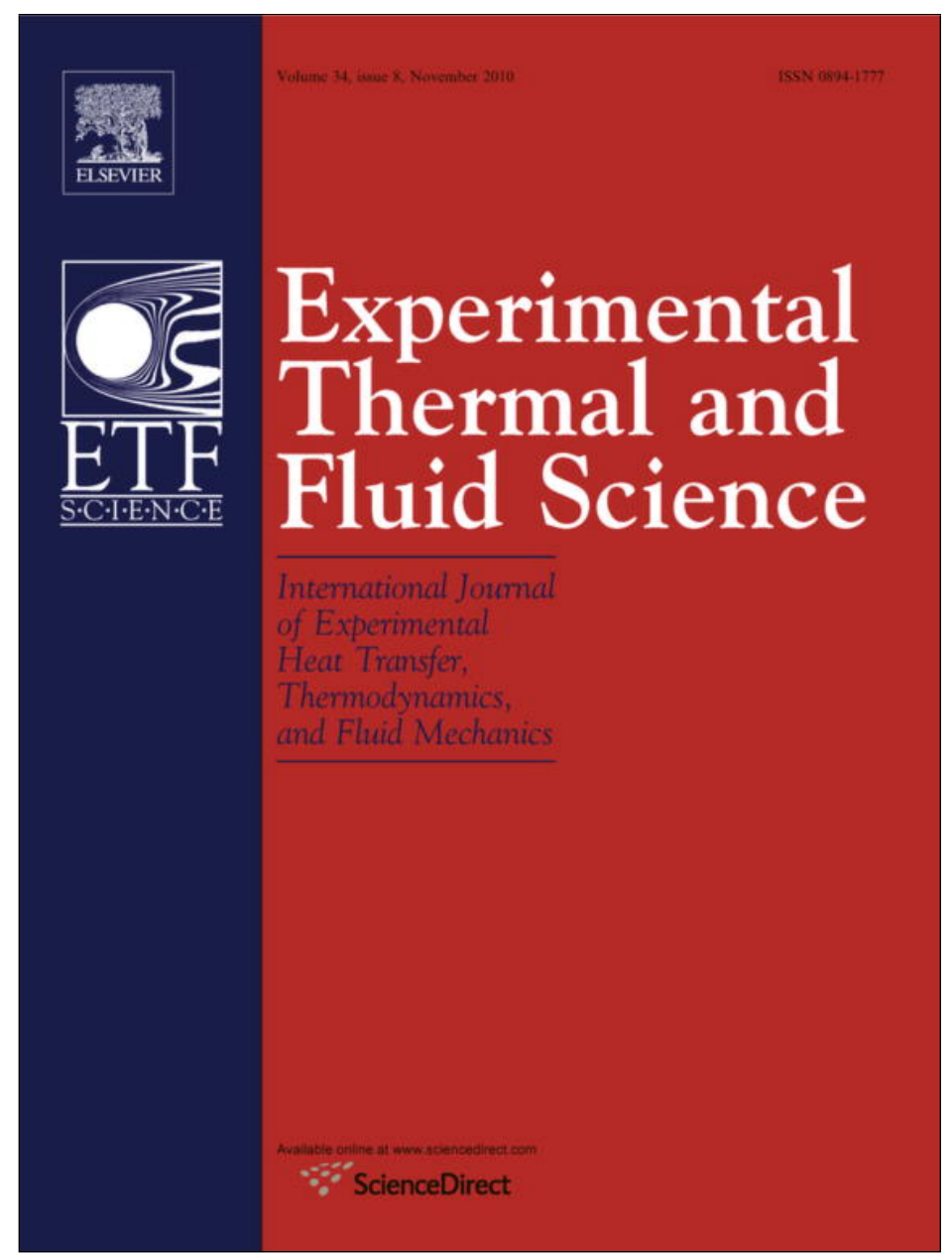

This article appeared in a journal published by Elsevier. The attached copy is furnished to the author for internal non-commercial research and education use, including for instruction at the authors institution and sharing with colleagues.

Other uses, including reproduction and distribution, or selling or licensing copies, or posting to personal, institutional or third party websites are prohibited.

In most cases authors are permitted to post their version of the article (e.g. in Word or Tex form) to their personal website or institutional repository. Authors requiring further information regarding Elsevier's archiving and manuscript policies are encouraged to visit:

http://www.elsevier.com/copyright 


\title{
Investigation on average void fraction for air/non-Newtonian power-law fluids two-phase flow in downward inclined pipes
}

\author{
Jing-yu $\mathrm{Xu}^{*}$ \\ LHO, Institute of Mechanics, Chinese Academy of Sciences, Beijing 100190, China
}

\section{A R T I C L E I N F O}

\section{Article history:}

Received 13 June 2010

Received in revised form 14 July 2010

Accepted 15 July 2010

\section{Keywords:}

Gas-liquid flow

Non-Newtonian fluid

Average void fraction

Inclined downward pipes

\begin{abstract}
A B S T R A C T
The present work has been carried out to investigate on the average void fraction of gas/non-Newtonian fluids flow in downward inclined pipes. The influences of pipe inclination angle on the average void fraction were studied experimentally. A simple correlation, which incorporated the method of Vlachos et al. for gas/Newtonain fluid horizontal flow, the correction factor of Farooqi and Richardson and the pipe inclination angle, was proposed to predict the average void fraction of gas/non-Newtonian power-law stratified flow in downward inclined pipes. The correlation was based on 470 data points covering a wide range of flow rates for different systems at diverse angles. A good agreement was obtained between theory and data and the fitting results could describe the majority of the experimental data within $\pm 20 \%$.
\end{abstract}

(c) 2010 Elsevier Inc. All rights reserved.

\section{Introduction}

The simultaneous flow of gas-liquid two-phase through downward inclined pipes is encountered in a diverse range of processes industries and particularly in the petroleum industry. Because of the injection of polymeric substance into the well for increasing oil production, crude oil often shows the characteristics of nonNewtonian fluid. Therefore, oil production results in transportation of gas/non-Newtonian fluid two-phase flow over long distances. One of the critical unknown parameters involved in calculating the pressure gradient of two-phase flow is the void fraction. In recent years, considerable effort has been made to develop methods to predict the void fraction for gas/Newtonian fluid flow in inclined pipes [1-10]. Owing to the complexity and lack of understanding of the basic underling physics of the problem, the majority of the analyses are suggested by using the empirical and semi-empirical correlations. Unlike gas/Newtonain fluid inclined flow [11-13], there are few studies for predicting the void fraction of gas/nonNewtonian fluid flow in inclined pipes [14-16], especially for inclined downward stratified flow. Therefore, the purpose of this work is to study experimentally the gas/non-Newtonian fluid two-phase flow in inclined downward pipe and then to develop a simple model to predict the average void fraction of gas/non-Newtonian stratified downward inclined flow based on experimental data.

\footnotetext{
* Tel.: +86 108254 4179; fax: +861062561284.

E-mail addresses: xujingyu@imech.ac.cn, jinyu.xu@gmail.com
}

\section{Experimental set-up and fluid characteristics}

The experimental investigation in this work was conducted using Perspex tubing of $60 \mathrm{~mm}$ in diameter. The tube includes two $10 \mathrm{~m}$ long pipe branches connected by a U-bend that could be inclined to any angle, from a completely horizontal to a fully vertical position. The gamma densitometer installed at $5 \mathrm{~m}$ from the entry point measured gamma ray absorption which allowed the mean average void fraction in the pipe to be calculated. The test section was scanned for five separate periods of $60 \mathrm{~s}$ to obtain an average value of the void fraction. The gamma ray densitometer was calibrated by scanning a Plexiglass box which contains several water to gas ratios and thus gave different void fraction values to be used as calibration points. Furthermore, to verify the experimental data of the gamma ray densitometer, the results from the gamma densitometer have been compared well with the results obtained using quick closing valves with an average difference for all conditions about $5 \%$. Air originated from a compressor pump and was routed through a gas tank and a regulating valve to maintain a constant pressure, after which it passed through a gas mass flow-meter. The liquid phase was conveyed from the liquid phase tank and circulated through the system by a centrifugal pump. The volumetric flow rates of all phases were regulated independently and measured by a thermal mass flow-meter for the gas phase and an electromagnetic flow-meter for the liquid phase, respectively. Flow patterns were recorded using a high-speed video camera, and the flow patterns for each test condition were recorded and observed later in slow motion. The details of the flowloop could be found in the previous works [14]. 


\begin{tabular}{|llll|}
\hline \multicolumn{2}{l}{ Nomenclature } & & \\
$V$ & mean velocity, m/s & & \\
$V_{c l}$ & critical value of superficial liquid velocity, $\mathrm{m} / \mathrm{s}$ & $\varepsilon$ & average void fraction \\
$V_{s l}$ & superficial liquid velocity, m/s & $J$ & correction factor of Farooqi and Richardson \\
$V_{s g}$ & superficial gas velocity, $\mathrm{m} / \mathrm{s}$ & $k$ & fluid consistency coefficient, Pa. $\mathrm{s}^{\mathrm{n}}$ \\
$\mathrm{Re}_{M R}$ & Metzner-Reed Reynolds number & $n$ & flow behaviour index \\
& & $\tilde{h}$ & dimensionless film thickness \\
$G r e e k$ & & $D$ & pipe diameter, $(\mathrm{m})$ \\
$\dot{\gamma}$ & shear rate, $\mathrm{s}^{-1}$ & $\rho_{l}$ & liquid phase density, $\mathrm{kg} / \mathrm{m}^{3}$ \\
$\tau$ & shear stress, Pa & $\alpha$ & pipe inclination angle \\
& & $\sigma$ & surface tension, $\mathrm{N} / \mathrm{m}$ \\
\hline
\end{tabular}

Tap water was used as the Newtonian fluid and carboxymethyl cellulose (CMC) solutions with three different concentrations were used as the non/Newtonian fluids. As expected, CMC solutions in the present study were shear-thinning fluids whose rheology could be described by a two-parameter power-law fluid model. For a power-law fluid, the shear stress was related to the shear rate by:

$\tau=k(\dot{\gamma})^{n}$

where $\dot{\gamma}, k$ and $n$ were referred to as the shear rate, the fluid consistency coefficient and the flow behaviour index, respectively. The appropriate Reynolds number can be defined as [17]:

$\operatorname{Re}_{M R}=\frac{D^{n} V^{2-n} \rho_{l}}{8^{n-1} k\left(\frac{1+3 n}{4 n}\right)^{n}}$

where $V, D$ and $\rho_{1}$ were the fluid velocity, the pipe diameter and the density of liquid phase, respectively. The values of $k, n$ and other properties of the CMC solutions were given in Table 1. For the fluids used in this work, the rheological behaviour of CMC solutions was measured before and after each run at constant liquid flow rate. The average deviation of the effective viscosity was less than $4.8 \%$. Thus, the rheological behaviour of CMC solution can be assumed as constant when the concentration is fixed. A total of about 350 experimental data were measured for the average void fraction of five different inclination angles $\left(\alpha=-0^{\circ},-5^{\circ},-15^{\circ},-30^{\circ},-75^{\circ}\right)$ in horizontal and downward pipes.

\section{Results and discussions}

\subsection{Experimental observations}

In the range of investigations carried out, it has been found from visual observation that the main flow patterns are slug flow at $\alpha=-0^{\circ}$, annular flow at $\alpha=-75^{\circ}$ and stratified flow at $\alpha=-5^{\circ}$, $\alpha=-15^{\circ}$ and $\alpha=-30^{\circ}$, respectively. The most prominent feature is a preponderance of a stratified flow pattern in downward inclined pipes. Fig. 1 shows the influences of pipe inclination angle on the average void fraction for air/CMC-3 solution flow at a given superficial liquid velocity. It can be found that the increase of the inclination angle strongly affects on average void fraction. For the inclination angles of $\alpha=0^{\circ}$ and $\alpha=-5^{\circ}$ the average void fraction increases with superficial gas velocity increased. However, when the inclination angle has been further increased $\left(\alpha=-15^{\circ},-30^{\circ}\right.$, $-70^{\circ}$ ), the average void friction tends to reach constant values regardless of the changes of superficial gas velocity. Fig. 2 presents the average void fraction against inclination angles for air/CMC-3 solution flow at constant superficial velocities. It can be seen that, at given a couple of superficial velocities, the average void fraction tends to sharply increase with the increase of inclination angle. When the inclination angle is increased further, the average void fraction passes through a maximum and then decreases. Generally, in downward flow, the intermittent flow regime is replaced by the stratified flow and there are the high average void fraction observed in downward flow. Effects of viscosity on the dimensionless film thickness for gas-liquid downward inclined stratified flow at $\alpha=-15^{\circ}$ is depicted in Fig. 3. For a given superficial liquid velocity, the dimensionless film thickness increases as the liquid phase becomes more shear-thinning (i.e., lower value of $n$ ). Thus, the average void fraction decreases with increasing CMC concentration due to the increase of the liquid-side shear stress at the gas-liquid interface. For two-phase stratified flow in downward inclined pipe, the values of the average void fraction for air/CMC solutions systems are much lower than those for air/water system when having the same input conditions. The same phenomenon is also observed in the case of two-phase horizontal intermittent flow [14], but the difference is much higher in stratified flow regimes.

\subsection{Predicting model}

One of the methods used mostly to predict the average void fraction in a gas-liquid stratified flow is the model of Taitel and Dukler [18] for gas/Newtonian liquid flow and extended by Heywood and Charles [19] and Xu et al. [14] for gas/non-Newtonian liquid horizontal and inclined flows, respectively. Due to the computational complexity, they are inconvenient for estimating the average void fraction in practical engineering applications. In the present work, we attempt to develop a simple method to predict the average void fraction for gas-liquid stratified inclined flow. The model suggested in this work bases on the method of Vlachos et al. [20] in horizontal stratified flow and accounts for the characteristics of non-Newtonian power-law fluid to predict the average void fraction.

For gas/Newtonian fluid two-phase stratified flow in horizontal pipes, Vlachos et al. suggested the dimensionless film thickness at the pipe bottom using the following empirical correlation:

Table 1

Liquid phase's properties measured at $20^{\circ} \mathrm{C}$ and $0.101 \mathrm{MPa}$.

\begin{tabular}{lllll}
\hline Liquid phase & Concentration $(\mathrm{kg} / \mathrm{m})$ & Density, $\rho\left(\mathrm{kg} / \mathrm{m}^{3}\right)$ & Surface tension, $\sigma(\mathrm{N} / \mathrm{m})$ & Fluid consistency coefficient, $k\left(\right.$ Pa. $\left.{ }^{\mathrm{n}}\right)$ \\
\hline Water & - & 999.0 & 0.0712 & 0.001 \\
CMC-1 solution & 1.0 & 999.9 & 0.0714 & 0.089 \\
CMC-2 solution & 2.0 & 1000.0 & 0.0718 & 0.469 \\
CMC-3 solution & 3.0 & 1000.4 & 0.0727 & 0.972 \\
\hline
\end{tabular}




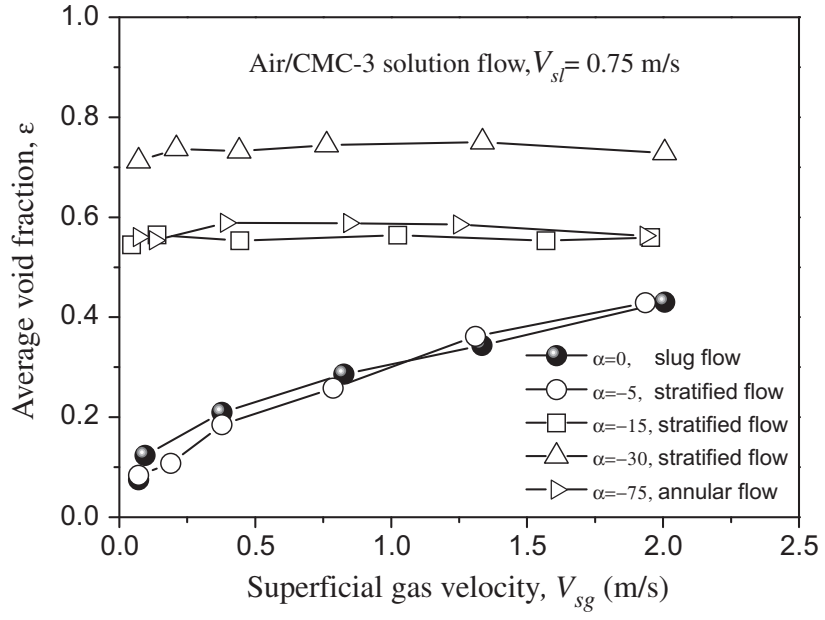

Fig. 1. The average void fraction measured for air/CMC-3 solution flow in different downward inclined pipes at constant superficial liquid velocity.

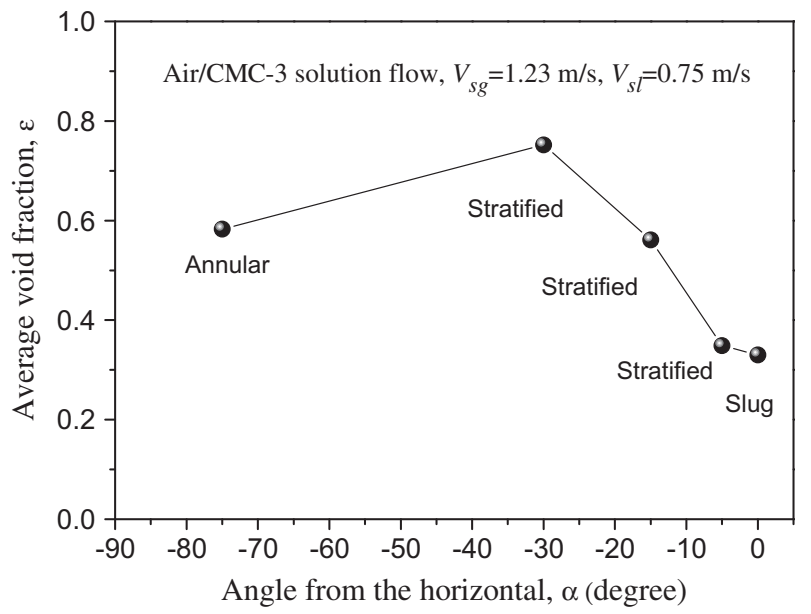

Fig. 2. The average void fraction against inclination angles for air/CMC-3 solution flow at constant superficial velocities.

$\tilde{h}=\frac{h}{D}=f\left(k, V_{s l}, V_{s g}\right)=k \frac{V_{s l}^{0.35}}{V_{s g}^{0.65}}$

where $k=1.5(\mathrm{~m} / \mathrm{s})^{0.3}$ and $\tilde{h}=h / D$ is the dimensionless film thickness in stratified flow. $h$ and $D$ are the average film thickness and the pipe diameter. Once the dimensionless film thickness is obtained, the average void fraction can be calculated by:

$\varepsilon=\frac{1}{\pi}\left[\cos ^{-1}(2 \tilde{h}-1)-(2 \tilde{h}-1) \sqrt{1-(2 \tilde{h}-1)^{2}}\right]$

For gas/non-Newtonian fluid horizontal flow, Farooqi and Richardson [21] modified the Lockhart-Martinelli parameter [22] to analyse experimental data. They proposed a correction factor defined as:

$J=\left(\frac{V_{s l}}{V_{c l}}\right)^{1-n}$

where $V_{c l}$ is the critical value of superficial liquid velocity when laminar flow ceases to exist. This value can be estimated by setting the Reynolds number, calculated by using Eq. (2), equal to 2000. By introducing the correction factor $(J)$ into the Lockhart-Martinelli parameter, they caused the holdup data of gas/non-Newtonian fluid

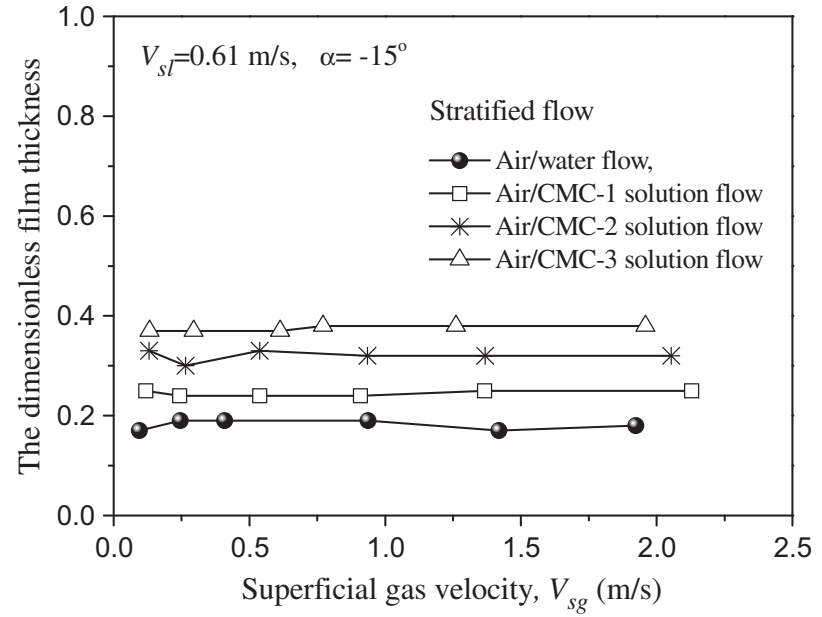

Fig. 3. Effects of viscosity on the dimensionless film thickness $(\tilde{h})$ for gas-liquid downward inclined stratified flow at $\alpha=-15^{\circ}$.

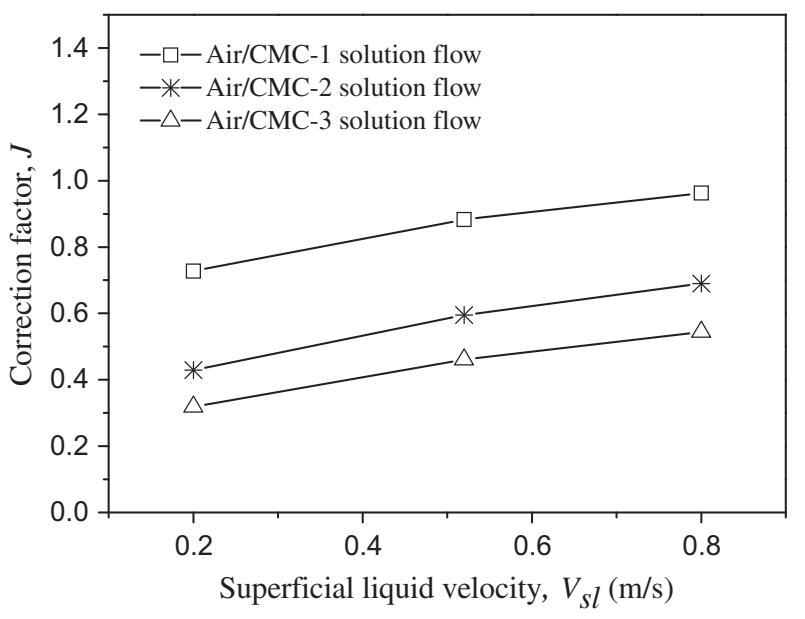

Fig. 4. Influences of both fluid viscosity and superficial liquid velocity on the correction factor of Farooqi and Richardson.

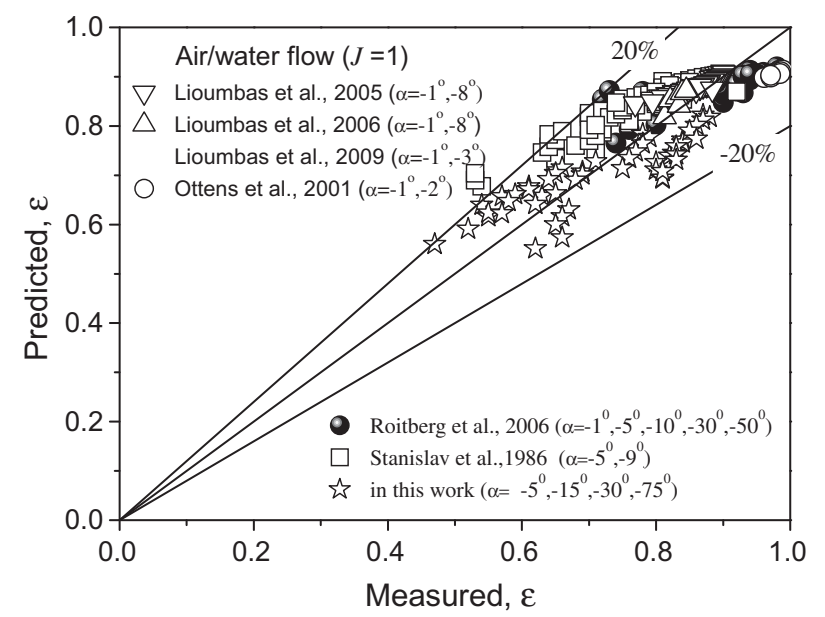

Fig. 5. The average void fraction predicted by the model against the average void fraction experimentally obtained in this work and for others systems reported in the literature: gas/Newtonian fluid system. 


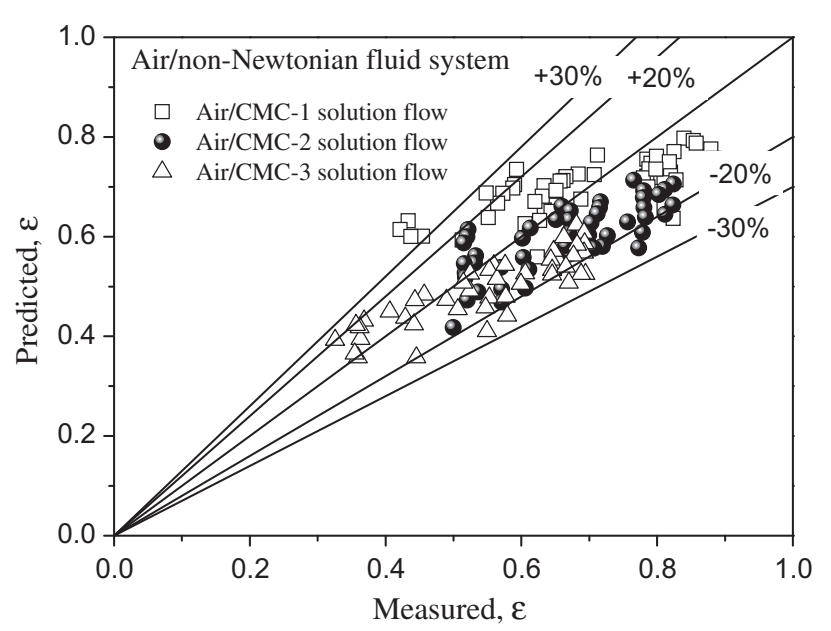

Fig. 6. The average void fraction predicted by the model against the average void fraction experimentally obtained: gas/non-Newtonian fluid system.

flow to be close to those of the gas/Newtonian fluid flow. Fig. 4 shows the influences of both fluid viscosity and superficial liquid velocity on the correction factor $(J)$. It can be seen in Fig. 4 that, with the increases of superficial liquid velocity, the changes of $J$ in three systems show a similar trend and all of the curves are similar to the linear with a same slope. In Fig. 3, The changes of the dimensional film thickness with the increases of superficial velocity appear a similar trend. By introducing $J$ into Eq. (3), we can adjust the dimensional film thickness predicted dependent on the changes of $J$. Here, $J$ reflects the characteristics of non-Newtonian fluid for a gas and liquid system [15]. Furthermore, considering the influences of inclination angles on average void fraction for predicting dimensionless film thickness in gas/non-Newtonian stratified flow, a general structure of the correlation can be defined by incorporating Eq. (3), the correction factor $(J)$ and the inclination angle for predicting the dimensionless film thickness of gas/non-Newtonian fluid in inclined stratified flow. The multiple regression analysis of the 470 experimental data in this work and those in the literature gives the following correlation:

$\tilde{h}=\frac{h}{D}=f\left(k, V_{s l}, V_{s g}, \alpha, J\right)=k(\sin (-\alpha))^{-0.15} \frac{V_{s l}^{0.42}}{V_{s g}^{0.07}} J^{-0.75}$

where $k=0.28(\mathrm{~m} / \mathrm{s})^{-0.36}$ and $\alpha<0^{0}$.

A large number of experimental data has been collected from the literature $[1,7,10-13]$ to verify the correlation suggested. A comparison of the theoretical predictions obtained from the Eqs. (6) and (4) for the average void fraction with experimental data in downward inclined stratified flow, for air/water system and air/non-Newtonian fluid systems, are given in Figs. 5 and 6, respectively. A good agreement is obtained between theory and data and the fitting results can describe the majority of the experimental data within $\pm 20 \%$.

\section{Conclusions}

The present study has attempted to investigate on the average void fraction of gas/non-Newtonian fluid flow in downward inclined pipes. The influences of pipe inclination angle on the average void fraction were studied experimentally. A new correlation for the average void fraction was proposed for gas/ non-Newtonian power-law fluids stratified flow in downward inclined pipes. The correlation incorporated the method of Vlachos et al. for gas/Newtonain fluid horizontal flow, the correction factor of Farooqi and Richardson and the pipe inclination angle. The correlation was based on 470 data points covering a wide range of flow rates for different systems at diverse angles. A good agreement was obtained between the predicted and experimental results.

\section{Acknowledgment}

The author gratefully acknowledge that the work described here was financially supported by the National Natural Science Foundation of China (No. 10902114).

\section{References}

[1] J.F. Stanislav, S. Kokal, M.K. Nich, Gas liquid flow in downward and upward inclined pipes, Can. J. Chem. Eng. 64 (1986) 881-890.

[2] S.L. Kokal, J.F. Stanislav, An experimental study of two phase flow in slightly inclined pipes - II. Liquid holdup and pressure drop, Chem. Eng. Sci. 44 (1989) 681-693.

[3] P.L. Spedding, D.R. Spence, N.P. Hands, Prediction of holdup in two phase gasliquid inclined flow, Chem. Eng. J. 45 (1990) 55-74.

[4] P.L. Spedding, Holdup prediction in vertical upwards to downwards flow, Dev. Chem. Eng. Mineral Process 5 (1997) 43-60.

[5] P. Coddington, R. Macian, A study of the performance of average void fraction correlations used in the context of drift-flux two-phase flow models, Nucl. Eng. Design 215 (2002) 199-216.

[6] H. Shi, J.A. Holmes, L.J. Durlofsky, K. Aziz, L.R. Diaz, B. Alkaya, G. Oddie, Driftflux, modeling of multiphase flow in wellbores, SPE J (March) (2005) 24-33.

[7] E. Roitberg (Trostinetsky), L. Shemer, D. Barnea, Application of a borescope to studies of gas-liquid flow in downward inclined pipes, Int. J. Multiphase Flow 32 (2006) 499-516.

[8] M.A. Woldesemayat, A.J. Ghajar, Comparison of average void fraction correlations for different flow patterns in horizontal and upward inclined pipes, Int. J. Multiphase Flow 33 (2007) 347-370.

[9] E. Grolman, J.M.H. Fortuin, Liquid hold-up Pressure gradient, and flow patterns in inclined gas-liquid pipe flow, Exp. Therm. Fluid Sci. 15 (1997) 174-182.

[10] M. Ottens, H.C.J. Hoefsloot, P.J. Hammersma, Correlations predicting liquid hold-up and pressure gradient in steady state (nearly) horizontal co-current gas-liquid pipe flow, Trans. IChem. 79 (2001) 581-592.

[11] J.S. Lioumbas, S.V. Paras, A.J. Karabelas, Co-current stratified gas-liquid downflow- Influence of the liquid flow field on interfacial structure, Int. J. Multiphase Flow 31 (2005) 869-896.

[12] J.S. Lioumbas, A.A. Mouza, S.V. Paras, Effect of surfactant additives on cocurrent gas-liquid downflow, Chem. Eng. Sci. 61 (2006) 4605-4616.

[13] J.S. Lioumbas, C. Kolimenos, S.V. Paras, Liquid layer characteristics in gas-liquid flow in slightly inclined pipes: effect of non-ionic surfactant additives, Chem. Eng. Sci. 64 (2009) 5162-5172.

[14] J. Xu, Y. Wu, Z. Shi, L. Lao, D. Li, Studies on two-phase co-current air/nonNewtonian shear-thinning fluid flows in inclined smooth pipes, Int. J. Multiphase Flow 33 (2007) 948-969.

[15] R.P. Chhabra, J.F. Richardson, Non-Newtonian flow and applied rheology, second ed., Butterworth Heinemann, Oxford, 2008.

[16] J. Xu, Y. Wu, A simple model for predicting the average void fraction of gas/ non-Newtonian fluid intermittent flows in upward inclined pipes, Chem. Eng. Comm. 196 (2009) 746-753.

[17] A.B. Metzner, J.C. Reed, Flow of non-Newtonian fluids-correlation of the laminar transition, and turbulent-flow regions, AIChE J. 1 (1955) 434-440.

[18] Y. Taitel, A.E. Dukler, A model for prediction flow regime transition in horizontal and near horizontal gas-liquid, AICHE J. 22 (1976) 47-55.

[19] N. Heywood, M.E. Charles, The stratified flow of gas and non-Newtonian liquid in horizontal pipes, Int. J. Multiphase Flow 5 (1979) 341-352.

[20] N.A. Vlachos, S.V. Paras, A.J. Karabelas, Prediction of holdup axial pressure gradient and wall shear stress in wavy stratified and stratified/atomization gas/liquid flow, Int. J. Multiphase Flow 25 (1999) 365-376.

[21] S.I. Farooqi, J.F. Richardson, Horizontal flow of air and liquid (Newtonian and non-Newtonian) in a smooth pipe Part I: A correlation for average liquid holdup, Trans. IChemE 60 (1982) 292-322.

[22] R. Lockhart, R. Martinelli, Proposed correlation of data for isothermal twophase, two-component flow in pipes, Chem. Eng. Prog. 45 (1949) 39-48. 